\title{
Numerical and experimental investigation on the depressurization capacity of a new type of depressure-dominated jet mill bit
}

\author{
Xu-Yue Chen ${ }^{1,2} \cdot$ Tong Cao $^{1} \cdot$ Kai-An Yu ${ }^{1} \cdot$ De-Li Gao ${ }^{1} \cdot$ Jin Yang $^{1} \cdot$ Hong-Shu Wei $^{3}$
}

Received: 14 September 2019 / Published online: 16 June 2020

(c) The Author(s) 2020

\begin{abstract}
Efficient cuttings transport and improving rate of penetration (ROP) are two major challenges in horizontal drilling and extended reach drilling. A type of jet mill bit (JMB) may provide an opportunity to catch the two birds with one stone: not only enhancing cuttings transport efficiency but also improving ROP by depressuring at the bottom hole. In this paper, the JMB is further improved and a new type of depressure-dominated JMB is presented; meanwhile, the depressurization capacity of the depressure-dominated JMB is investigated by numerical simulation and experiment. The numerical study shows that low flow-rate ratio helps to enhance the depressurization capacity of the depressure-dominated JMB; for both depressurization and bottom hole cleaning concern, the flow-rate ratio is suggested to be set at approximately $1: 1$. With all other parameter values being constant, lower dimensionless nozzle-to-throat-area ratio may result in higher depressurization capacity and better bottom hole cleaning, and the optimal dimensionless nozzle-to-throat-area ratio is at approximately 0.15. Experiments also indicate that reducing the dimensionless flow-rate ratio may help to increase the depressurization capacity of the depressure-dominated JMB. This work provides drilling engineers with a promising tool to improve ROP.
\end{abstract}

Keywords Horizontal drilling $\cdot$ Jet mill bit $\cdot$ Bottom hole depressurization $\cdot$ Bottom hole flow field $\cdot$ Rate of penetration

\section{Introduction}

Horizontal drilling and extended reach drilling have been considered as an ideal technique for developing unconventional oil \& gas reservoirs (Gao et al. 2009; Chen et al. 2016c; Chen and Gao 2018). However, as the low cuttings carrying capacity of horizontal drilling and extended reach drilling, cuttings bed easily forms, which may result in complications such as pipe sticking and wellbore plugging (Chen

Edited by Yan-Hua Sun

Xu-Yue Chen

chenxuyue2011@163.com; chenxuyue@cup.edu.cn

De-Li Gao

gaodeli@cup.edu.cn

1 MOE Key Laboratory of Petroleum Engineering, China University of Petroleum (Beijing), Beijing 102249, China

2 Shaanxi Cooperative Innovation Center of Unconventional Oil and Gas Exploration and Development, Xi' an Shiyou University, Xi' an 710065, Shaanxi, China

3 CNOOC China Limited, Shenzhen Branch, Shenzhen 518067, Guangdong, China et al. 2014; Yeu et al. 2019; Pang et al. 2019). Moreover, the mechanical energy provided by the surface to drive the bit has a great transmission loss in horizontal drilling due to cuttings bed and high friction, the cuttings hold-down effect also may increase because the drilling fluid frictional pressure and bottom hole pressure increase with the wellbore extending, and these result in a low rate of penetration (ROP). Therefore, it is a great challenge for the horizontal drilling and extended reach drilling to achieve an efficient cuttings transport and a high ROP. Over the past several decades, numerous studies have been conducted toward addressing cuttings transport problems, experimental observations and field experience indicated that cuttings size is one of the most critical factors on cuttings transport, and it is generally recognized that smaller cuttings are easier to keep in suspension for transporting (Ford et al. 1990; Walker and Li 2000; Ahmed 2001). Duan et al. (2008) observed that with polymeric drilling fluids and combined with drillpipe rotation, smaller cuttings are easier to transport in horizontal wellbore, and the transport efficiency of small cuttings $(0.45 \mathrm{~mm})$ is nearly twice as high as that of large cuttings (1.4 mm and $3.3 \mathrm{~mm}$ ). Kamyab and Rasouli (2016) observed that small cuttings (smaller than $0.42 \mathrm{~mm}$ ) have much 
higher transport efficiency in the drilling fluids with high viscosity in horizontal wellbore than that of large cuttings (2.36 $\mathrm{mm}$ and $4.7 \mathrm{~mm}$ ). Hakim et al. (2018) reported that the highest cuttings transport efficiency for 5\% concentration of water-based mud polypropylene in horizontal wellbore was recorded at approximately $96 \%$ for cutting sizes of $0.50-0.99 \mathrm{~mm}$ in six different sizes of drilled cuttings ranging from 0.5 to $4.0 \mathrm{~mm}$. Epelle et al. (2018) reported that small cuttings transport efficiency can be improved remarkably by improving in the rheological properties of the drilling fluid, while large cuttings still pose a challenge to the wellbore cleaning process despite the rheological enhancement. More recently, Heshamudin et al. (2019) observed that smaller cuttings are easier to transport at all pipe rotations and polypropylene bead concentrations in horizontal wellbore. Previous studies indicated that small cuttings have much higher transport efficiency than large cuttings. This triggered an idea of comminuting the cuttings right after they are generated, thereby cuttings accumulation in horizontal drilling may be eliminated (Chen et al. 2016b). Chen et al. (2016a, b, and c) developed a type of jet mill bit (JMB); this tool proffers a promising solution to the cuttings accumulation problem in horizontal drilling by comminuting cuttings into dustlike scale right after the cuttings are generated in the bottom hole. As it is, the JMB provides a promising solution to catch two birds with one stone: not only enhancing cuttings transport efficiency but also improving ROP by depressuring at the bottom hole. Through depressuring at the bottom hole, the JMB can lower the stress on rock surface, minimize cuttings hold-down effect, and improve cuttings cleaning capacity, thus increasing the ROP (Li et al. 2010; Shi et al. 2018). In 2019, JMB was improved by adding junk slots around to allow cuttings to flow through the annulus instead of accumulating at the top of the JMB while tripping out and therefore avoid sticking (Cao et al. 2019). This improvement reduces the risk of sticking while tripping out and increases the feasibility of field application of JMB in horizontal drilling. However, junk slots around the JMB can allow cuttings and drilling fluid flowing through the annulus, it may weaken the depressurization capacity and drilling performance of the JMB.

As Chen et al. (2016a) reported, the JMB is developed based on the jet comminution technique, in which particles can be broken into smaller ones instantly by high-speed impacts of these particles against a target. When comminution chamber and target are removed from the jet mill of the JMB, it is a jet pump. Namely, the function of depressurization of the JMB is based on the jet pump theory. The jet pump was introduced in the oil-and-gas industry in 1970 and widely used for underbalanced drilling (Zhu et al. 2013; Yang et al. 2012). There were many kinds of tools for underbalanced jet-pump drilling, such as an annular jet-pump depressure joint (Hooper 1986), a jet-pump bit (Lott 1998), an annular jet pump fixed inside casing (Suryanarayana et al. 2004; Hughes 2005), an annular jet pump with drill string rotation (Hosie et al. 2005), and so on. However, all these tools' depressurization capacity is limited as the jet pump is far from the bottom hole and there is always a big clearance in annulus. In this paper, a new type of depressure-dominated JMB is presented; meanwhile, the depressurization capacity of the depressure-dominated JMB is investigated by numerical simulation and experiment.

\section{Principle of the depressure-dominated jet mill bit}

Figure 1 shows a sketch of the depressure-dominated JMB. Drilling fluid is injected into the depressure-dominated JMB and then divided into two streams. One stream flows through the bottom hole cuttings agitation and cleaning nozzles toward the bottom hole. Asymmetric jet stirs the bottom hole cuttings into a highly turbulent flow. The highly turbulent cuttings flow through the cuttings-suction channel into the mixing chamber under the lift of bottom hole flow and the suction of backward jet nozzles (Chen et al. 2016a). The depressure-dominated JMB has small junk slots or flowby that conventional bits have around the bit to allow cuttings and drilling fluid to flow through the annulus between the bit and wellbore (Fig. 2). Please note that the junk slots or flowby of the depressure-dominated JMB is much smaller than that of the conventional bits and so is the clearance in the annulus. As Cao et al. (2019) reported, the cuttings will flow out inside the bit through the cuttings-suction channel instead of the small junk slots and annulus. The other stream flows through the backward jet nozzles, mixing chamber, throat, dissociating and comminution tube, and diffuser toward the annulus between open hole and drill pipe. This stream flows through the backward jet nozzles, generates a

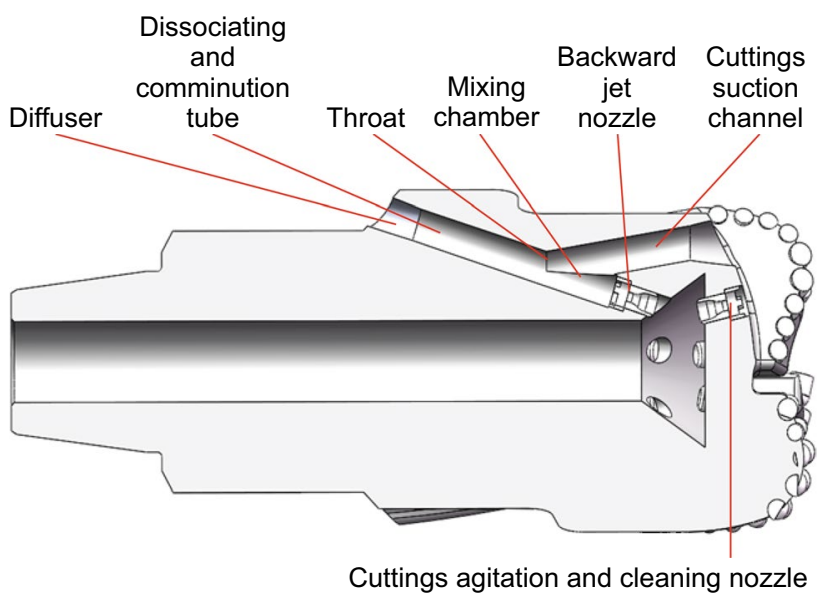

Fig. 1 Sketch of the depressure-dominated JMB 


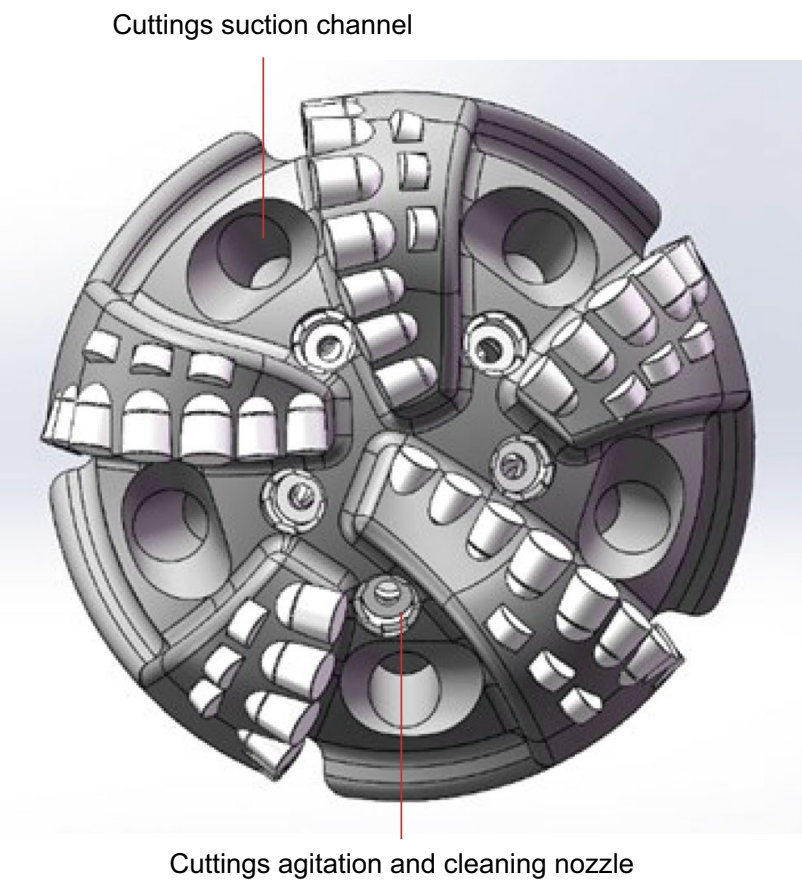

Fig. 2 Crown of the depressure-dominated JMB

high-velocity jet, and lowers the pressure at the bottom hole. It can suck and entrap the bottom hole drilling fluid together with cuttings into the dissociating and comminution tube. Then, cuttings are accelerated and broken by dissociating, shearing, fluid wedging, and collision with each other in the dissociating and comminution tube (Müller et al. 1995; Fisher 2006). Finally, the small cuttings flow into the annulus through the diffuser.

\section{Numerical analysis of the depressurization capacity}

\subsection{Governing equations}

Compared with the conventional JMB, the depressure-dominated JMB enhances the function of depressurization, while weakens the function of jet comminution. In order optimally design the depressure-dominated JMB, the depressurization capacity and its controlling effect factors are quantitatively analyzed by numerical simulation. Several basic assumptions are adopted:

(1) The fluid is defined as constant incompressible fluid;

(2) Fluid density and temperature changes are ignored;

(3) The effect of cuttings on the flow field is ignored;

(4) Bit rotation is not considered.
Mass conservation equation and the Reynolds-averaged Navier-Stokes (RANS) are used as the control equations (Wang 2004). The standard $k-\varepsilon$ turbulence model is adopted to close the RANS equation (Zhang et al. 2011).

The mass conservation equation:

$\frac{\partial \rho}{\partial t}+\nabla \cdot(\rho U)=0$

In the above equation, $\rho$ is the fluid density, $t$ is the time, and $U$ is the fluid velocity.

Momentum equation:

$$
\left(\frac{\partial \rho \mathbf{u}_{i}}{\partial t}+\rho \mathbf{u}_{j} \frac{\partial \mathbf{u}_{i}}{\partial x_{j}}\right)=\rho \mathbf{f}_{i}-\frac{\partial \rho}{\partial x_{i}}+\frac{\partial}{\partial x_{j}}\left[\mu_{\mathrm{eff}}\left(\frac{\partial \mathbf{u}_{i}}{\partial x_{j}}+\frac{\partial \mathbf{u}_{j}}{\partial x_{i}}\right)\right]
$$

where

$\mu_{\mathrm{eff}}=\mu+\mu_{\mathrm{t}}$

$\mu_{\mathrm{t}}=C_{\mu} \rho \frac{k^{2}}{\varepsilon}$

In the above equation, $\mathbf{u}$ is the velocity tensor, $\mathbf{f}$ is the force tensor of mass, $x$ is the Cartesian coordinates, $i$ and $j$ are the directions of coordinates, $\mu_{\text {eff }}$ is the effective viscosity, $\mu$ is the fluid viscosity, $\mu_{\mathrm{t}}$ is the turbulence viscosity, $C_{\mu}$ is a constant, $k$ is the turbulent kinetic energy, and $\varepsilon$ is the turbulence dissipation rate.

Turbulent transport equations (Standard $k-\varepsilon$ model):

$$
\begin{aligned}
\frac{\partial}{\partial t}(\rho k)+\frac{\partial}{\partial x_{j}}\left(\rho k \mathbf{u}_{i}\right)= & \frac{\partial}{\partial x_{j}}\left[\left(\mu+\frac{\mu_{\mathrm{t}}}{\sigma_{\mathrm{k}}}\right) \frac{\partial k}{\partial x_{j}}\right] \\
& +G_{\mathrm{k}}+G_{\mathrm{b}}-\rho \varepsilon-Y_{\mathrm{M}}+S_{\mathrm{k}}
\end{aligned}
$$

$$
\begin{aligned}
\frac{\partial}{\partial t}(\rho \varepsilon)+\frac{\partial}{\partial x_{j}}\left(\rho \varepsilon \mathbf{u}_{i}\right)= & \frac{\partial}{\partial x_{j}}\left[\left(\mu+\frac{\mu_{\mathrm{t}}}{\sigma_{\varepsilon}}\right) \frac{\partial \varepsilon}{\partial x_{j}}\right] \\
& +C_{1 \varepsilon} \frac{\varepsilon}{k}\left(G_{\mathrm{k}}+C_{3 \varepsilon} G_{\mathrm{b}}\right)-C_{2 \varepsilon} \rho \frac{\varepsilon^{2}}{k}+S_{\varepsilon}
\end{aligned}
$$

In the above equations, $\sigma_{\mathrm{k}}$ and $\sigma_{\varepsilon}$ are the turbulent Prandtl numbers of the $k$ and $\varepsilon$ equations, respectively, $G_{\mathrm{k}}$ represents the turbulent kinetic energy produced by the laminar velocity gradient, $G_{\mathrm{b}}$ is the turbulent kinetic energy generated by the buoyancy, $Y_{\mathrm{M}}$ is the result of fluctuations caused by excessive diffusion due to compressible turbulence, $S_{\varepsilon}$ and $S_{\mathrm{k}}$ are user-defined parameters, $C_{1 \varepsilon}, C_{2 \varepsilon}$, and $C_{3 \varepsilon}$ are constants. In the above equations, the empirical constants are given by the following values: $C_{\mu}=0.09, \sigma_{\mathrm{k}}=1.0, \sigma_{\varepsilon}=1.3, C_{1 \varepsilon}=1.44$, $C_{2 \varepsilon}=1.92$. 


\subsection{Simulation methods and model building}

In this work, an Ø215.9-mm (8.5 in.) depressure-dominated JMB with 5 blades, 5 backward jet nozzles, and 5 cuttings agitation and cleaning nozzles is used for numerical simulation. The slot size is expressed in Fig. $3, R_{\mathrm{i}}$ is the inner radius of the junk slots, $R_{\mathrm{o}}$ is the outer radius of the junk slots, and $L$ is the inner boundary arc length of the junk slots.

As Chen et al. (2016a) reported, the JMB has several basic nondimensional parameters, such as $M$, the dimensionless flow-rate ratio; $R$, the dimensionless nozzle-to-throatarea ratio; $\rho$, the dimensionless density ratio. According to the jet pump theory, the depressurization capacity may be greatly affected by $M, R, \rho$, and the jet velocity of the nozzles. In this work, the effect of cuttings on the flow field is ignored and so is $\rho$. Therefore, the effects of $M, R$, and the jet velocity of the nozzles on the depressurization capacity of the depressure-dominated JMB are modeled. The computation domain is shown in Fig. 4, and the fluid domain mesh is shown in Fig. 5.

\subsection{Boundary conditions and simulation results}

\subsubsection{The effects of dimensionless flow-rate ratio on the depressurization capacity}

Boundary conditions are given by: (1) The inlet cross sections is set as the velocity inlet boundary conditions, and

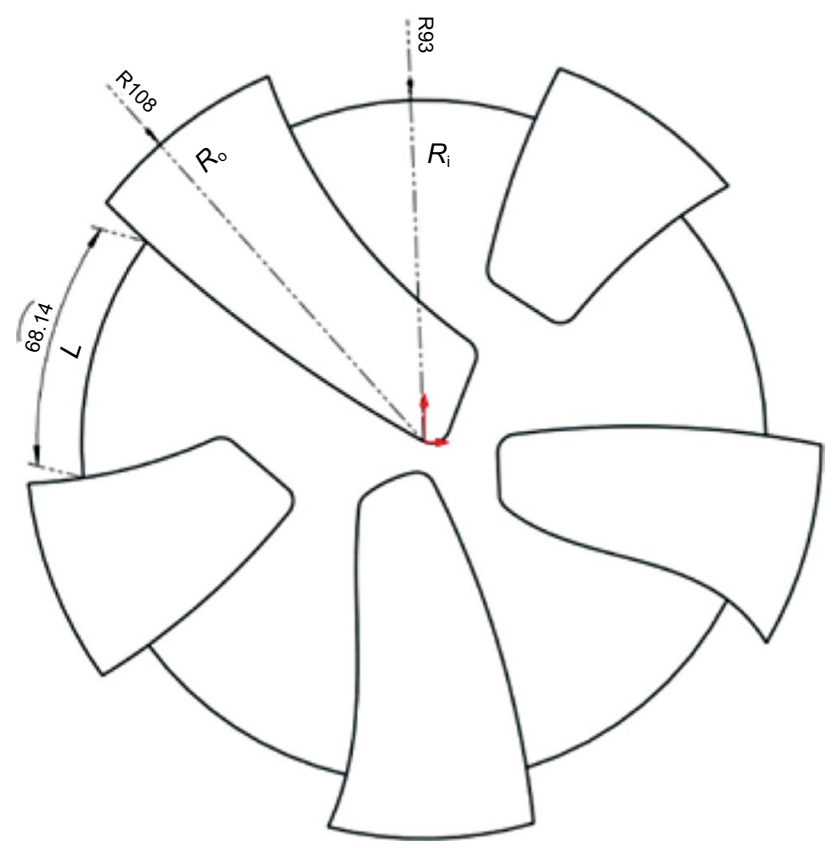

Fig. 3 Depressure-dominated JMB crown dimension drawing

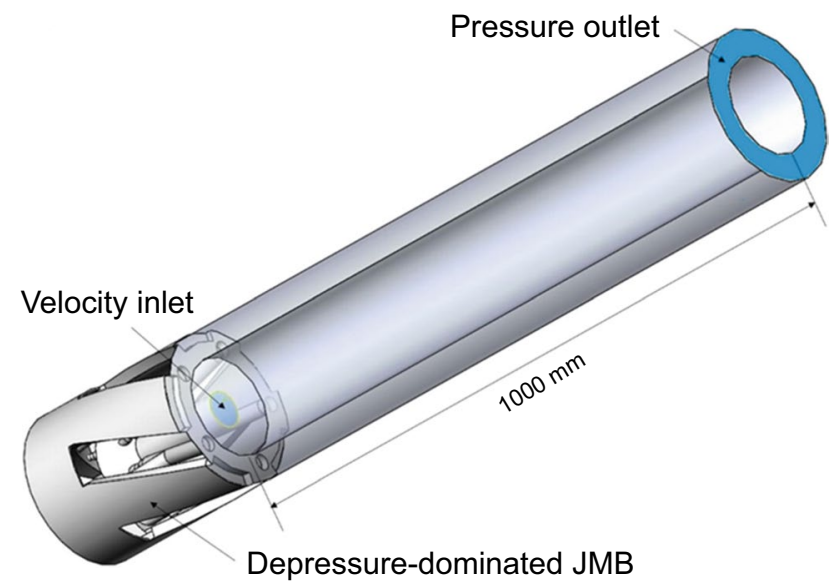

Fig. 4 The computation domain

the inlet velocity is set as $17.13 \mathrm{~m} / \mathrm{s}$; (2) the pressure outlet boundary conditions are chosen for the outlet cross sections, and the outlet pressure is set as $45 \mathrm{MPa}$; (3) the wall is set as the fixed wall boundary condition, and the wall is set as the standard wall. When the fluid displacement is given, $M$ and the jet velocity of the nozzles depend on the diameter of the nozzles. The diameter of nozzles and $M$ can be estimated as$$
\left\{\begin{aligned}
\pi\left[n_{1}\left(\frac{d_{1}}{2}\right)^{2}+n_{2}\left(\frac{d_{2}}{2}\right)^{2}\right] & =\frac{Q}{v} \\
\frac{n_{1} \pi\left(\frac{d_{1}}{2}\right)}{n_{2} \pi\left(\frac{d_{2}}{2}\right)} & =M
\end{aligned}\right.
$$

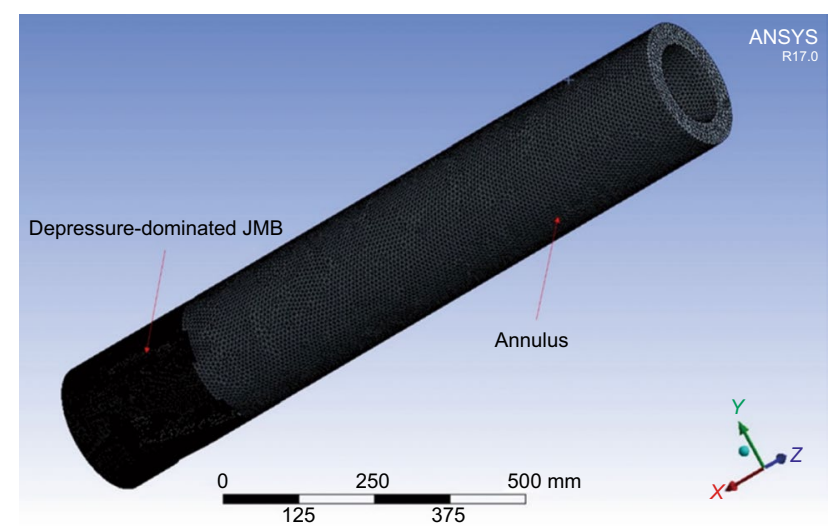

Fig. 5 The computation domain mesh 
In the equations, $n_{1}$ is the number of cuttings agitation and cleaning nozzles, $d_{1}$ is the diameter of the single cuttings agitation and cleaning nozzle, $Q$ is the fluid displacement, $v$ is the jet velocity of the nozzles, $n_{2}$ is the number of backward jet nozzles, and $d_{2}$ is the diameter of the single backward jet nozzle. In this case, the effects of dimensionless flow-rate ratio on the depressurization capacity are modeled based on different values of dimensionless flow-rate ratio; the parameters are shown in Table 1.
As shown in Fig. 6, with all other parameter values being constants, the bottom hole pressure almost decreases with the decrease in dimensionless flow-rate ratio. Compared with $M=2: 1$, the depressurization capacity of the depressure-dominated JMB is obvious when $M=1: 1, M=1: 2$, and $M=1: 3$. It means that higher fluid displacement from the backward jet nozzles than that from the cuttings agitation and cleaning nozzles may help to enhance the depressurization capacity of the depressure-dominated JMB. As there are

Table 1 Parameters for simulating the effects of dimensionless flow-rate ratio on the depressurization capacity

\begin{tabular}{llccc}
\hline $\begin{array}{l}\text { Dimensionless flow-rate } \\
\text { ratio }\end{array}$ & $\begin{array}{l}\text { Fluid displacement, } \\
\text { L/s }\end{array}$ & $\begin{array}{l}\text { Jet velocity of the noz- } \\
\text { zles, } \mathrm{m} / \mathrm{s}\end{array}$ & $\begin{array}{l}\text { Diameter of the single cuttings agitation } \\
\text { and cleaning nozzle, mm }\end{array}$ & $\begin{array}{l}\text { Diameter of the single } \\
\text { backward jet nozzle, mm }\end{array}$ \\
\hline $2: 1$ & 35 & 49.36 & 10.97 & 7.76 \\
$1: 1$ & 35 & 74.00 & 7.76 & 7.76 \\
$1: 2$ & 35 & 98.64 & 5.49 & 7.76 \\
$1: 3$ & 111.01 & 4.48 & 7.76 \\
\hline
\end{tabular}

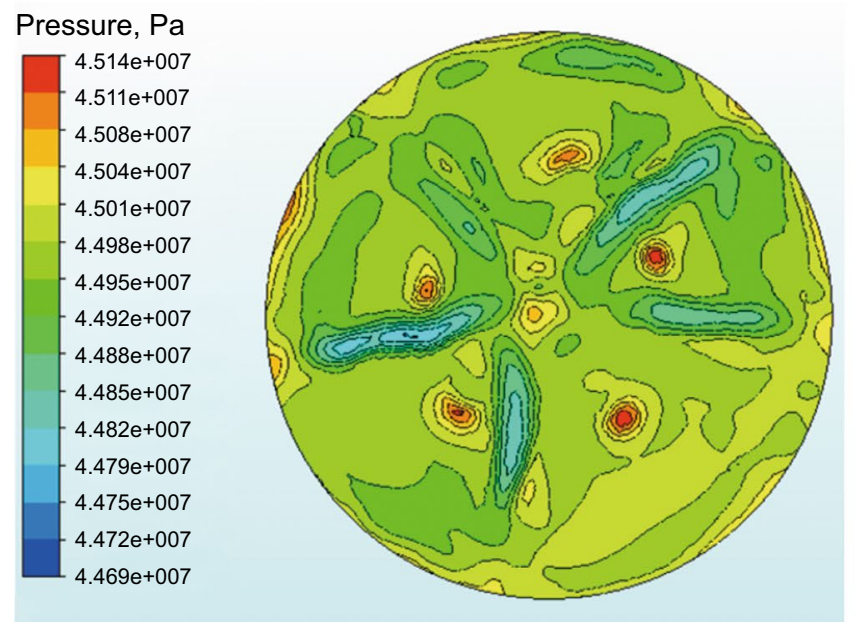

(a) $M=2: 1$

Pressure, $\mathrm{Pa}$

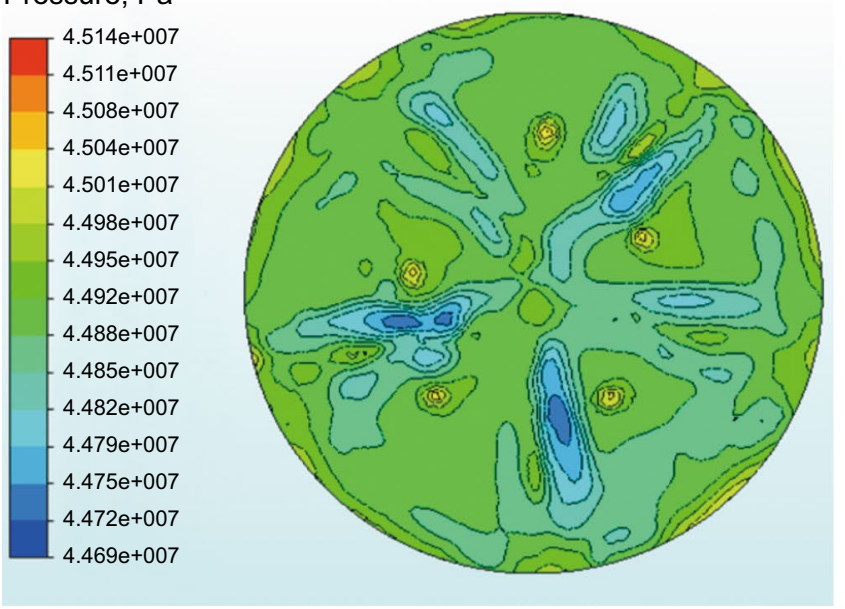

(c) $M=1: 2$

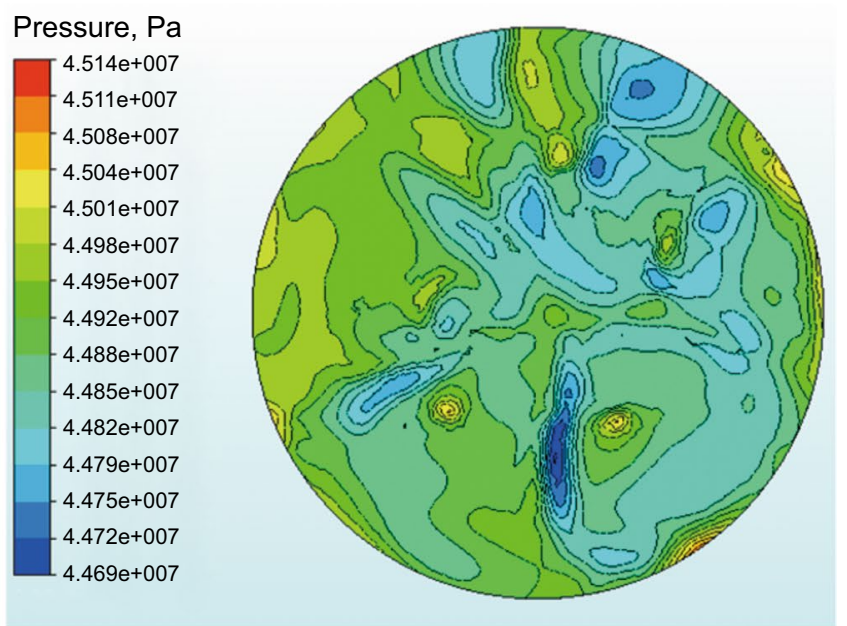

(b) $M=1: 1$

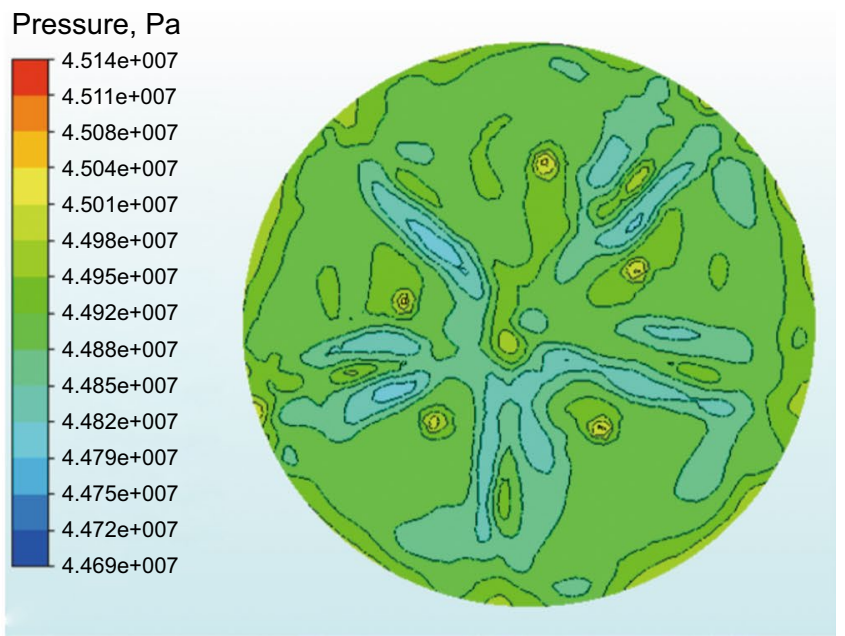

(d) $M=1: 3$

Fig. 6 Bottom hole pressure cloud at different dimensionless flow-rate ratios 


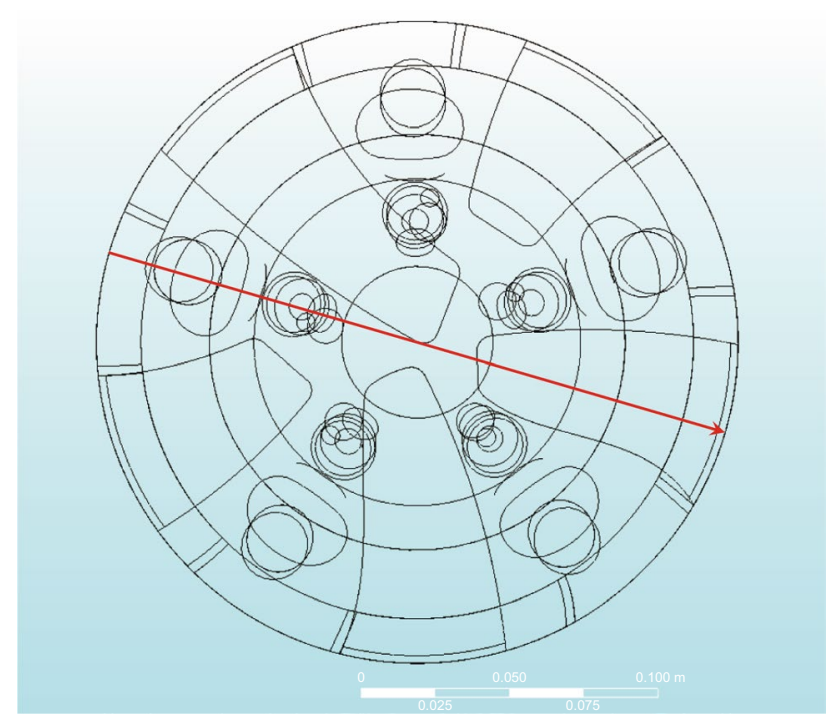

Fig. 7 Locations of fluid particles at the bottom hole along the direction of the depressure-dominated JMB diameter for pressure and velocity analysis

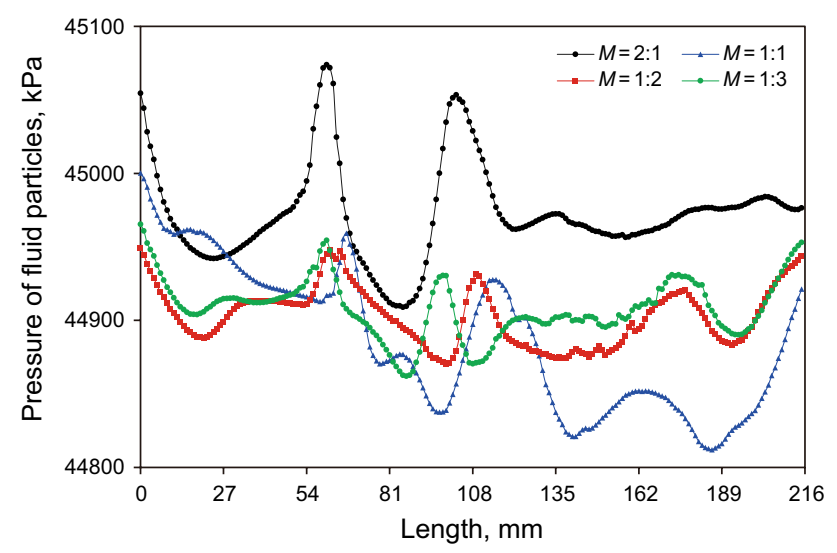

Fig. 8 The effects of $M$ on the pressure of fluid particles at the bottom hole along the direction of the depressure-dominated JMB diameter

small junk slots or flowby around the depressure-dominated JMB, excessively low $M$ will result in the backflow of the bottom hole fluid. It reduces the depressurization capacity of the depressure-dominated JMB. For $M=1: 1$, there is an obvious unevenness of the bottom hole pressure cloud; this can help cuttings removal under the bit and enhance bottom hole cleaning. In order to analyze the pressure and velocity of the fluid particles at the bottom hole, fluid particles along the direction of the depressure-dominated JMB diameter are selected for analyzing (see the red arrow shown in Fig. 7). When $M=1: 1$, the pressure of fluid particles at the bottom hole along the direction of the depressure-dominated JMB diameter is almost the lowest, and the velocity of fluid particles at the bottom hole along the direction of

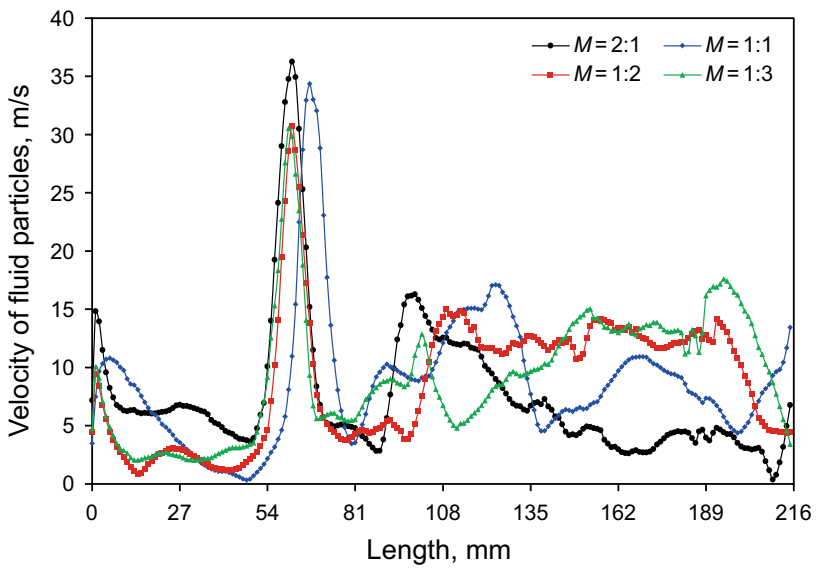

Fig. 9 The effects of $M$ on the velocity of fluid particles at the bottom hole along the direction of the depressure-dominated JMB diameter

Table 2 Parameters for simulating the effects of jet velocity on the depressurization capacity

\begin{tabular}{llcl}
\hline $\begin{array}{l}\text { Dimensionless } \\
\text { flow-rate ratio }\end{array}$ & $\begin{array}{l}\text { Diameter of the single } \\
\text { cuttings agitation and } \\
\text { cleaning nozzles and } \\
\text { backward jet nozzles, } \\
\text { mm }\end{array}$ & $\begin{array}{l}\text { Average jet } \\
\text { velocity, m/s }\end{array}$ & $\begin{array}{l}\text { Fluid dis- } \\
\text { placement, } \\
\text { L/s }\end{array}$ \\
\hline $1: 1$ & 5.76 & 134.32 & \\
$1: 1$ & 6.76 & 97.52 & 35 \\
$1: 1$ & 7.76 & 74.00 & 35 \\
$1: 1$ & 8.76 & 58.07 & 35 \\
\hline
\end{tabular}

the depressure-dominated JMB diameter fluctuates up and down (Figs. 8 and 9); this is helpful for bottom hole cleaning. Therefore, for both depressurization and bottom hole cleaning concern, approximately $M=1: 1$ is suggested for designing the depressure-dominated JMB.

\subsubsection{The effects of jet velocity on the depressurization capacity}

Boundary conditions are given as follows: (1) The inlet cross sections are set as the velocity inlet boundary conditions, and the inlet velocity is set as $17.13 \mathrm{~m} / \mathrm{s}$; (2) the pressure outlet boundary conditions are chosen for the outlet cross sections, and the outlet pressure is set as $45 \mathrm{MPa}$; (3) the wall is set as the fixed wall boundary condition, and the wall is set as standard wall. With the dimensionless flowrate ratio being a constant, the effects of jet velocity on the depressurization capacity can be investigated by changing the diameter of cuttings agitation and cleaning nozzles and backward jet nozzles. When setting $M=1: 1$, the jet velocity at different diameters of cuttings agitation and cleaning nozzles and backward jet nozzles is shown in Table 2. 


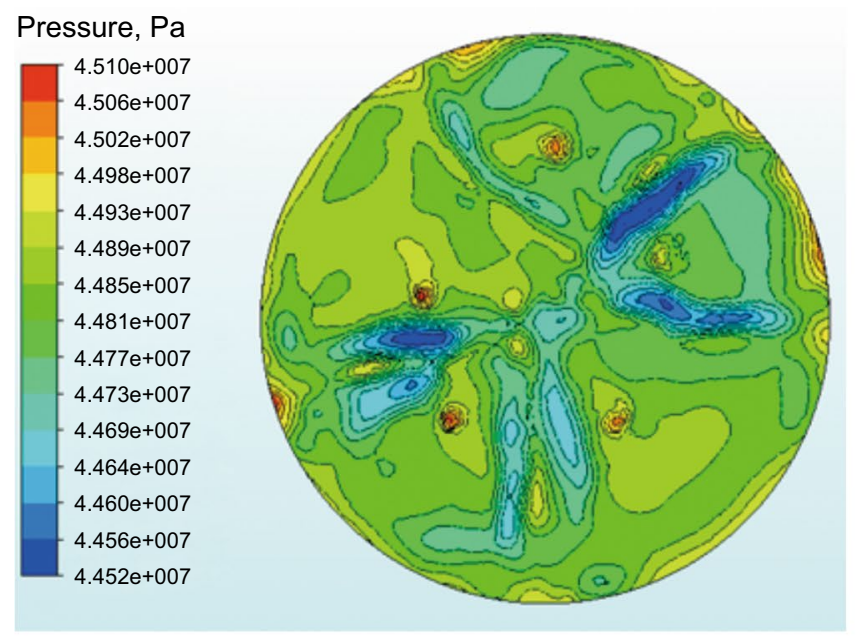

(a) Average jet velocity is $134.32 \mathrm{~m} / \mathrm{s}$

Pressure, $\mathrm{Pa}$

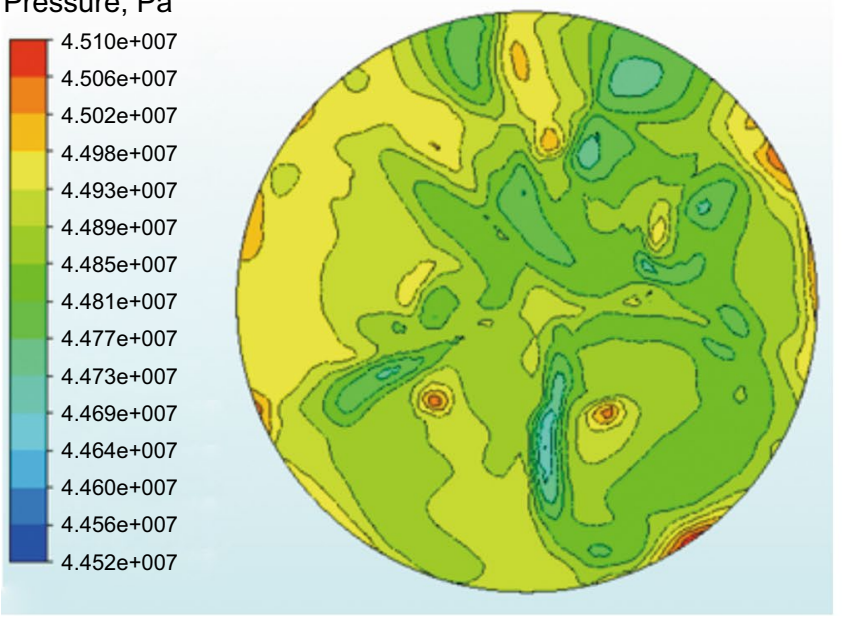

(c) Average jet velocity is $74.00 \mathrm{~m} / \mathrm{s}$

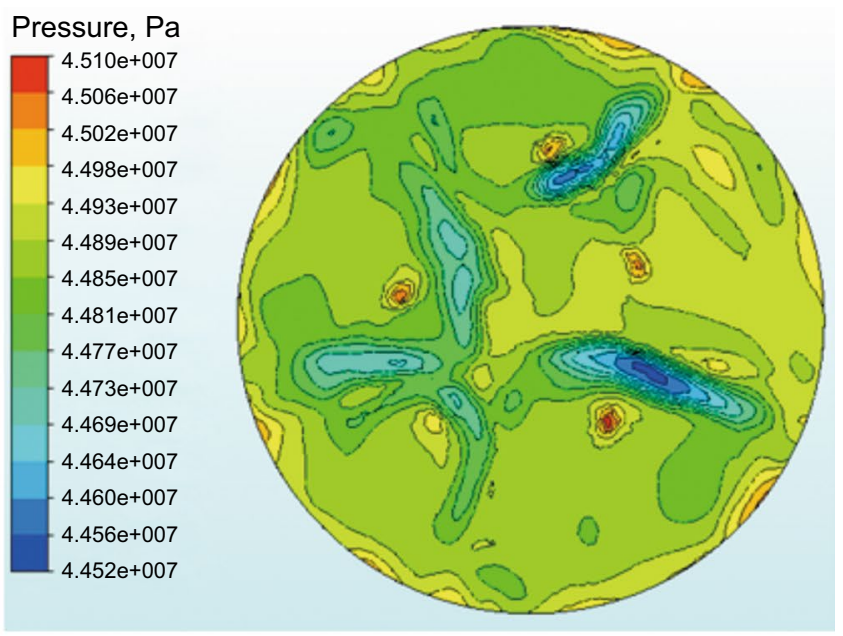

(b) Average jet velocity is $97.52 \mathrm{~m} / \mathrm{s}$

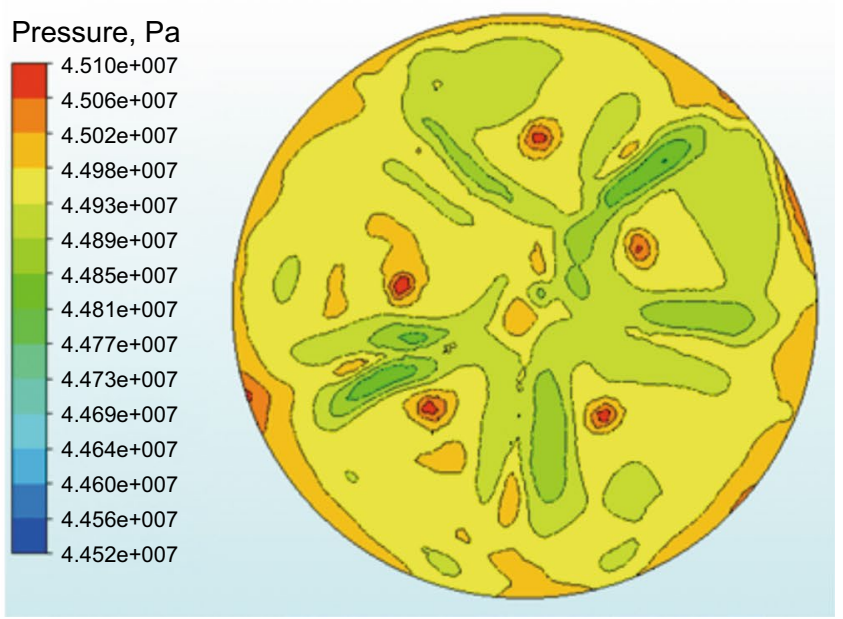

(d) Average jet velocity is $58.07 \mathrm{~m} / \mathrm{s}$

Fig. 10 Bottom hole pressure cloud at different average jet velocity

As shown in Fig. 10, with all other parameter values being constants, the bottom hole pressure increases with the increase in the nozzle diameter and the decrease in the average jet velocity. Large average jet velocity will result in the unevenness of the bottom hole pressure, and the larger average jet velocity leads to larger unevenness of the bottom hole pressure. The unevenness of the bottom hole pressure can help cuttings removal under the bit and enhance bottom hole cleaning. As Fig. 11 shows, when the average jet velocity is over $97.52 \mathrm{~m} / \mathrm{s}$, the pressure of fluid particles at the bottom hole along the direction of the depressure-dominated JMB diameter fluctuates significantly. As indicated in Fig. 12, the velocity of fluid particles at the bottom hole along the direction of the depressure-dominated JMB diameter fluctuates up and down, and the increase in the average jet velocity will lead to an increase in the fluctuant. It reveals that higher average jet

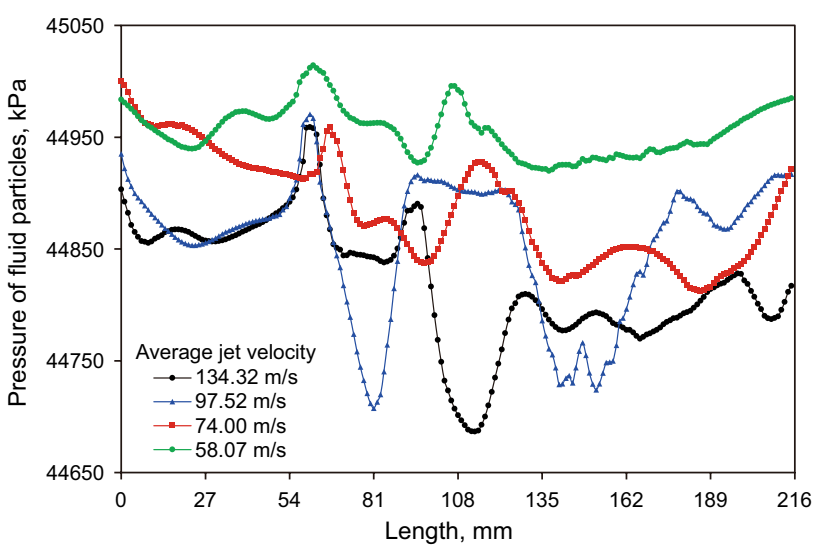

Fig. 11 The effects of jet velocity on the pressure of fluid particles at the bottom hole along the direction of the depressure-dominated JMB diameter 


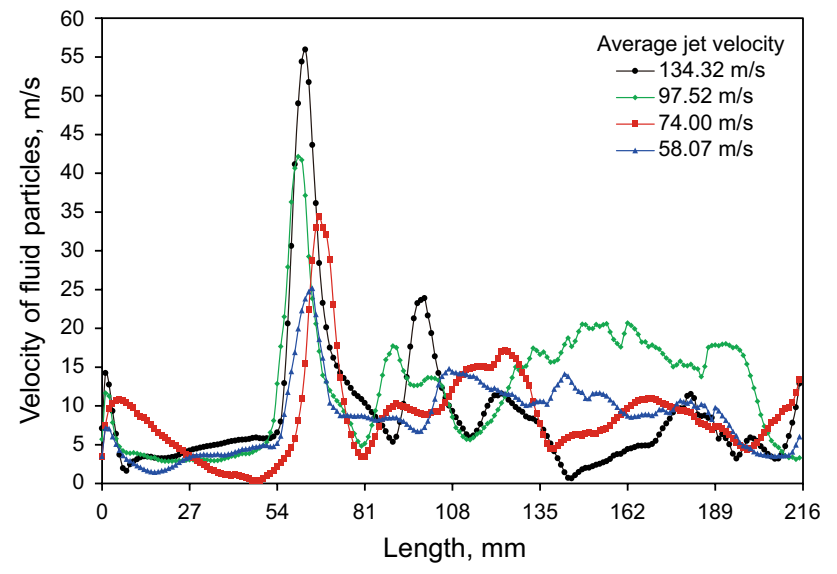

Fig. 12 The effects of jet velocity on the velocity of fluid particles at the bottom hole along the direction of the depressure-dominated JMB diameter

velocity results in higher depressurization capacity of the depressure-dominated JMB.

\subsubsection{The effects of dimensionless nozzle-to-throat-area ratio on the depressurization capacity}

Boundary conditions are given as follows: (1) The inlet cross sections are set as the velocity inlet boundary conditions, and the inlet velocity is set as $16.50 \mathrm{~m} / \mathrm{s}$; (2) the pressure outlet boundary conditions are chosen for the outlet cross sections, and the outlet pressure is set as $60 \mathrm{MPa}$; (3) the wall is set as the fixed wall boundary condition, and the wall is set as the standard wall. With the jet velocity of the nozzles being a constant and $M=1: 1$, the effects of dimensionless nozzle-to-throat-area ratio on the depressurization capacity can be investigated by changing the dimensionless nozzle-to-throat-area ratio.

As shown in Fig. 13, with all other parameter values being constants, the bottom hole pressure increases with the increase in the dimensionless nozzle-to-throat-area ratio. Compared with other dimensionless nozzle-to-throat-area ratios, the depressurization capacity of the depressure-dominated JMB is obvious when $R=0.15$. It also reveals that low dimensionless nozzle-to-throat-area ratio will result in the unevenness of the bottom hole pressure, and the lower dimensionless nozzle-to-throat-area ratio leads to larger unevenness of the bottom hole pressure. The unevenness of the bottom hole pressure can help cuttings removal under the bit and enhance bottom hole cleaning. As indicated in Figs. 14 and 15 , when $R=0.15$, the pressure of fluid particles at the bottom hole along the direction of the depressuredominated JMB diameter is almost the lowest and fluctuates significantly; meanwhile, the velocity of fluid particles at the bottom hole along the direction of the depressure-dominated JMB diameter is high. This is helpful for bottom hole cleaning. Therefore, lower dimensionless nozzle-to-throatarea ratio will result in higher depressurization capacity and better bottom hole cleaning of the depressure-dominated JMB.

\section{Experimental analysis of the depressurization capacity}

\subsection{Experimental procedure}

Experimental investigation on the depressurization capacity of the depressure-dominated JMB is conducted. A full-scale experimental system is set up (Fig. 16), and the schematic of the experimental system is shown in Fig. 17. The experimental system mainly consists of a mud tank, pipelines, a mud pump, a wellbore, a depressure-dominated JMB, pressure transducers, and a computer for collecting data. The maximum displacement of the mud pump is $25 \mathrm{~L} / \mathrm{s}$. The diameter of the depressure-dominated JMB is $215.9 \mathrm{~mm}$, and the depressure-dominated JMB has 5 blades, 5 backward jet nozzles, and 5 cuttings agitation and cleaning nozzles (Fig. 17). The inner diameter of the wellbore is $220.5 \mathrm{~mm}$, and the length of the wellbore is $1.2 \mathrm{~m}$. Three pressure transducers are installed in the experimental system: pressure transducer 1 is installed at the drill pipe near the depressure-dominated JMB in order to monitor the injecting pressure of the depressuredominated JMB; pressure transducer 2 is installed at the bottom hole near cuttings-suction channel of the depressure-dominated JMB in order to monitor bottom hole pressure; pressure transducer 3 is installed at the wellbore above the depressure-dominated JMB in order to monitor the annulus pressure. After eliminating the pressure difference owning to the height difference of the pressure transducers, the pressure difference between pressure transducers 1 and 2 indicates the depressurization capacity of the depressure-dominated JMB under various experimental conditions. Circulating drilling fluid through the drill pipe, depressure-dominated JMB, and the wellbore, the depressurization capacity of the depressure-dominated JMB can be tested. In this case, the effects of dimensionless flow-rate ratio on the depressurization capacity of the depressure-dominated JMB are analyzed by blocking the cuttings agitation and cleaning nozzles with choke plugs. The designed parameter combinations of dimensionless flow-rate ratio for the experiment are shown in Table 3.

\subsection{Experimental results and discussion}

As shown in Fig. 18, when the depressure-dominated JMB has 5 backward jet nozzles and 5 cuttings agitation 

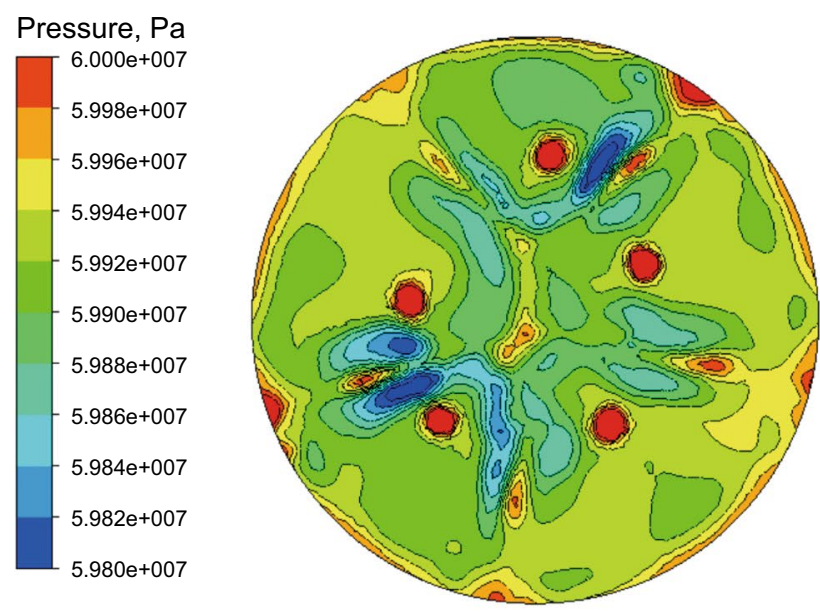

(a) $R=0.15$
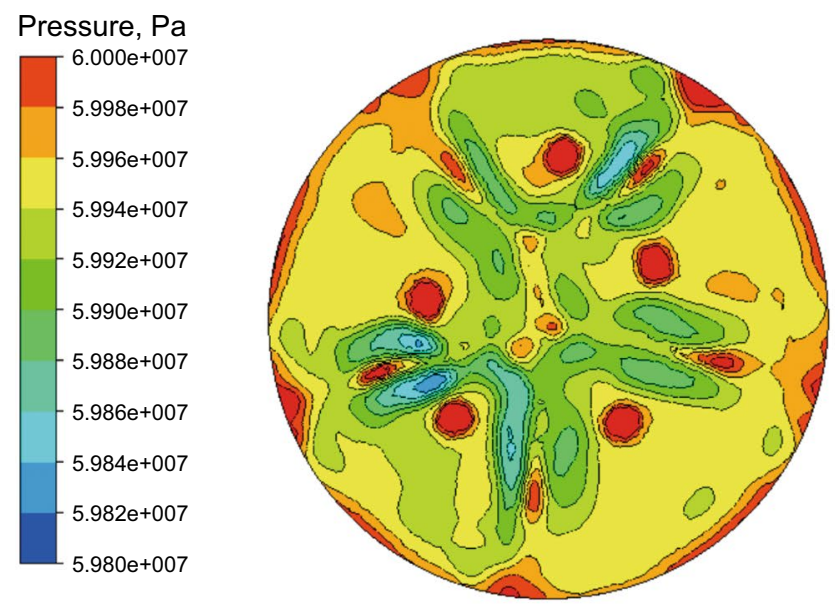

(c) $R=0.25$

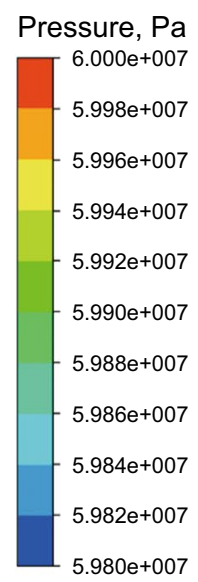

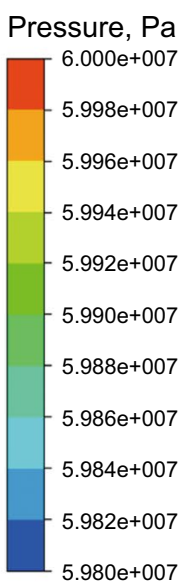

$5.980 e+007$

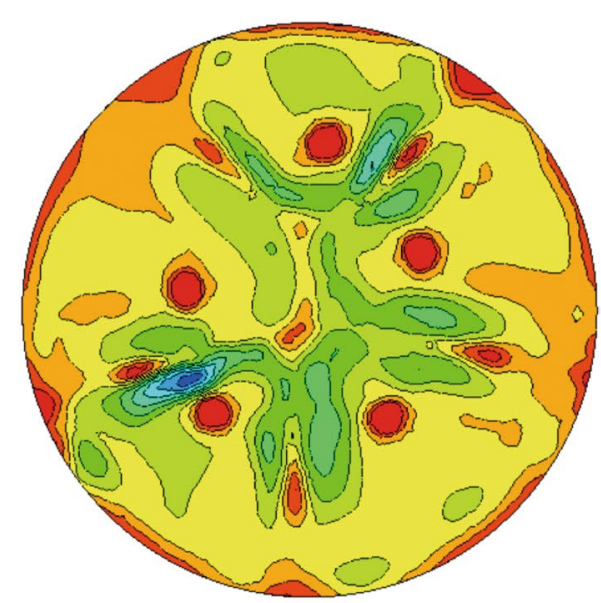

(e) $R=0.35$
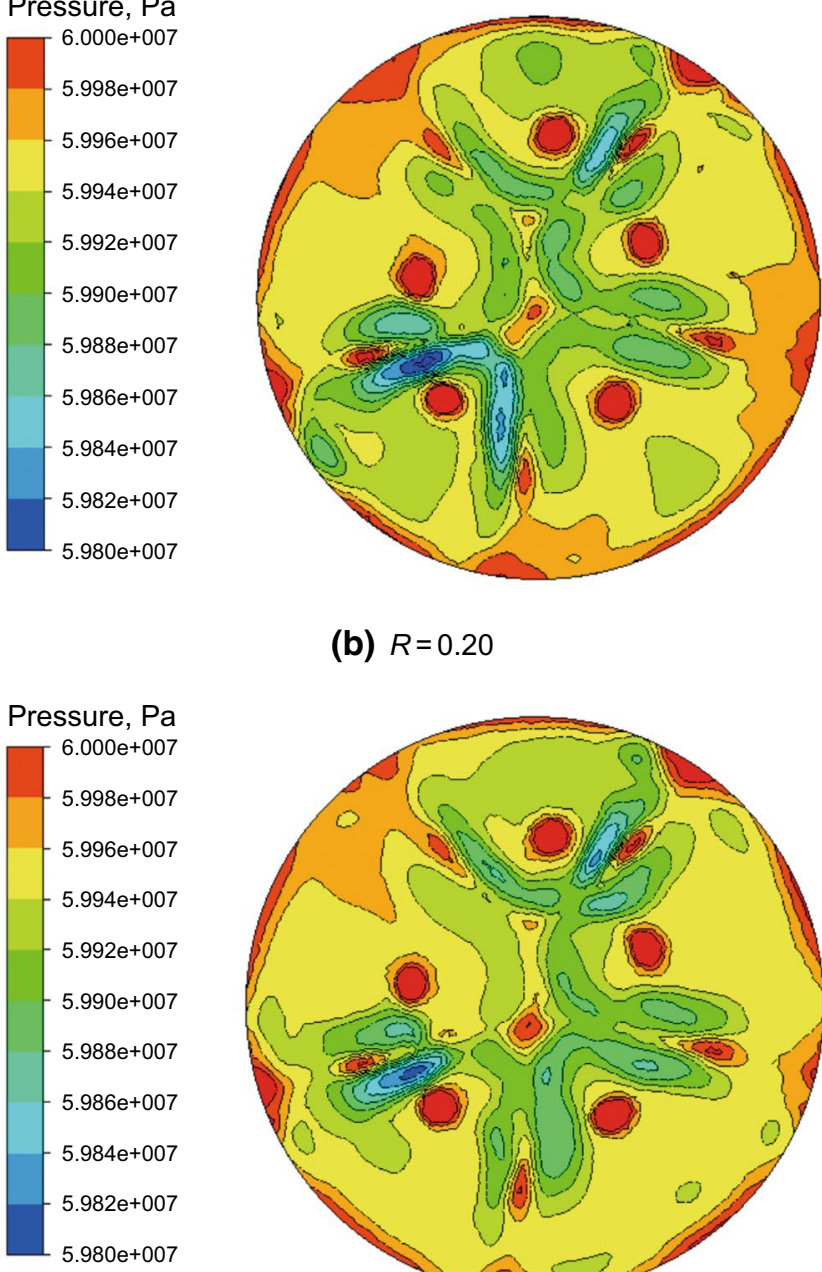

(b) $R=0.20$

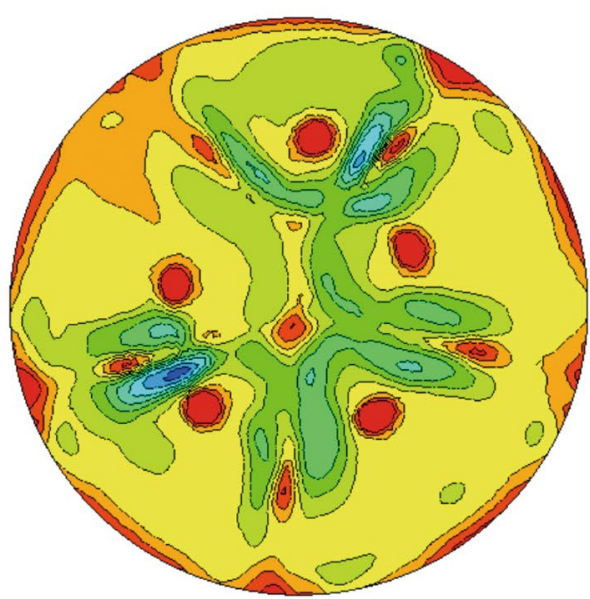

(d) $R=0.30$
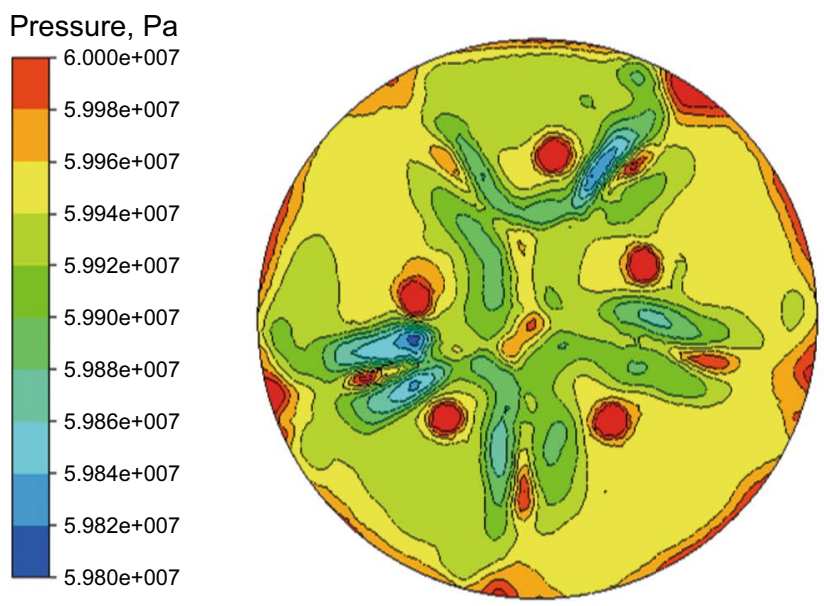

(f) $R=0.40$

Fig. 13 Bottom hole pressure cloud at different dimensionless nozzle-to-throat-area ratios 


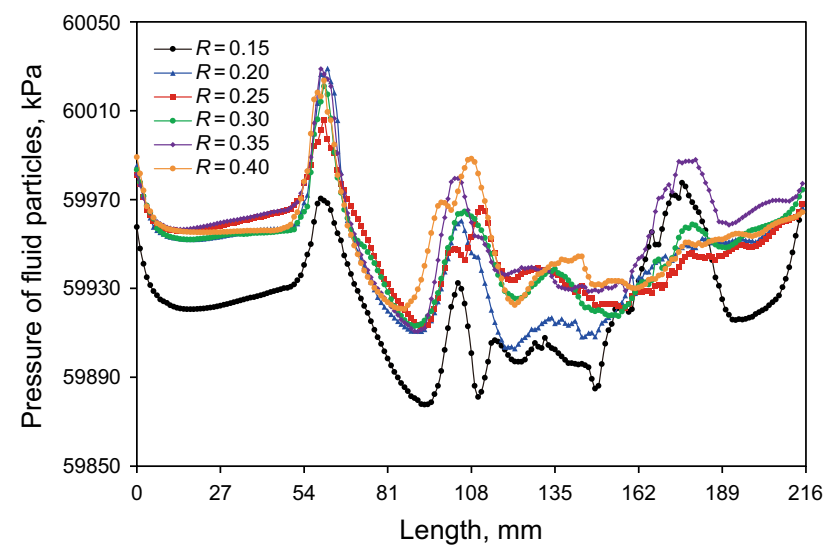

Fig. 14 The effects of $R$ on the pressure of fluid particles at the bottom hole along the direction of the depressure-dominated JMB diameter

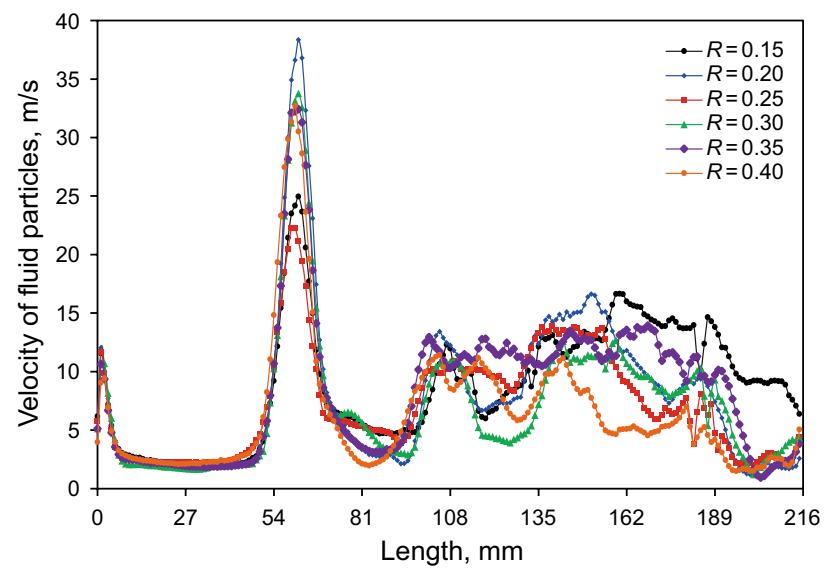

Fig. 15 The effects of $R$ on the velocity of fluid particles at the bottom hole along the direction of the depressure-dominated JMB diameter and cleaning nozzles, namely $M=1: 1$, both the annulus pressure and the bottom hole pressure increase with the increase in injecting pressure, and the pressure difference between the annulus pressure and the bottom hole pressure also increases. When the injecting pressure is lower than $1.5 \mathrm{MPa}$, the pressure difference increases slowly. When the injecting pressure is over $1.5 \mathrm{MPa}$, it increases obviously, and it rockets when the injecting pressure is over 2.0 MPa. Compared with the pressure difference, the pressure difference-to-annulus pressure ratio is relatively maintained stable. It goes up and down with the increase in injecting pressure while the value is within the range of $0.03-0.1$. When one of the cuttings agitation and cleaning nozzles is blocked with a choke plug, namely $M=4: 5$, both the annulus pressure and the bottom hole pressure still increase with the increase in injecting pressure, and the pressure difference between the annulus pressure and the bottom hole pressure also increases obviously (Fig. 19). When the injecting pressure is lower than 2.1 MPa, the pressure difference increases slowly. When the injecting pressure is over $2.1 \mathrm{MPa}$, it increases obviously, and it rockets when the injecting pressure is over 2.4 MPa. Compared with the pressure difference, the pressure difference-to-annulus pressure ratio is relatively maintained stable. It goes up and down with the increase in injecting pressure while the value is within the range of $0.02-0.15$.

As shown in Figs. 18b and 19b, with the injecting pressure increasing at the same condition, when one of the cuttings agitation and cleaning nozzles is blocked with a choke plug and the dimensionless flow-rate ratio reduces to $4: 5$ from $1: 1$, the ultimate pressure difference between the annulus pressure and the bottom hole pressure increases from 0.01 to $0.12 \mathrm{MPa}$, and the ultimate pressure difference-to-annulus

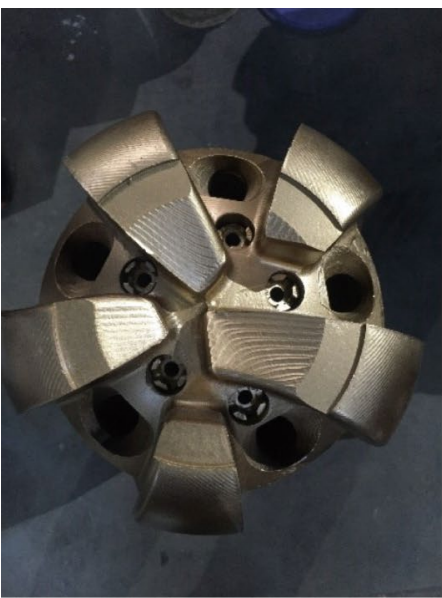

(a) Depressure-dominated JMB

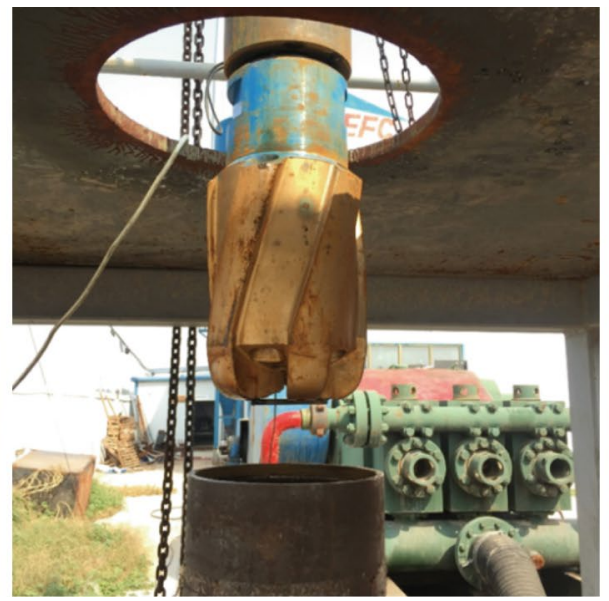

(b) Depressure-dominated JMB trips out

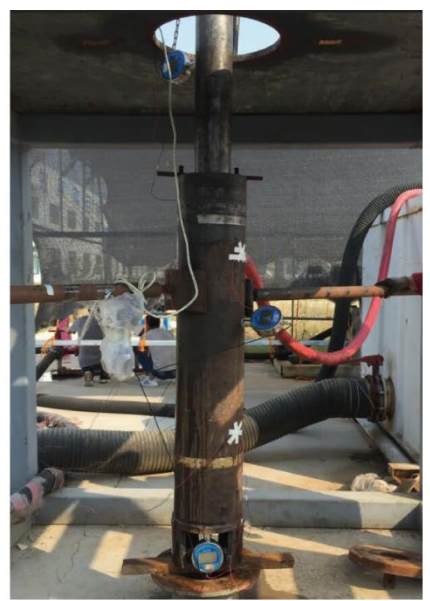

(c) Depressurization capacity test

Fig. 16 The full-scale experimental system 


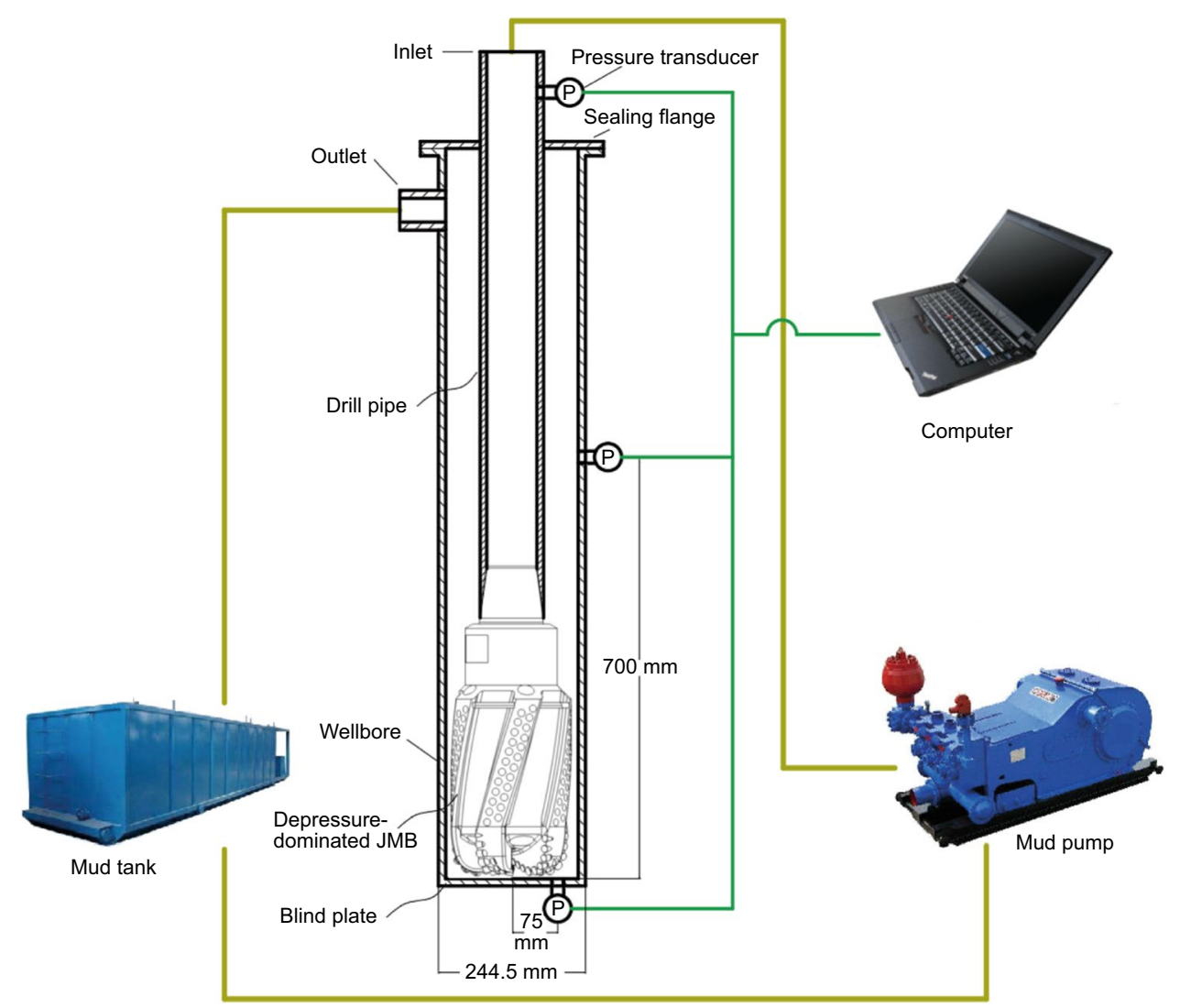

Fig. 17 Schematic of the experimental system

pressure ratio also increases from 0.092 to 0.113 . It indicates that at the same condition, reducing the dimensionless flowrate ratio may help to increase the depressurization capacity of the depressure-dominated JMB. This matches with the above numerical simulation results that higher fluid displacement from the backward jet nozzles than that from the cuttings agitation and cleaning nozzles may help to enhance the depressurization capacity of the depressure-dominated JMB. Moreover, the depressurization capacity of the depressure-dominated JMB increases with the injecting pressure (Figs. 18a and 19a). Due to the limits of the real allowable power of the mud pump and the pressure-proof of the pipeline of the laboratory-scale experimental rigs, please note

Table 3 The designed parameter combinations of dimensionless flow-rate ratio

\begin{tabular}{lll}
\hline $\begin{array}{l}\text { Dimensionless } \\
\text { flow-rate ratio for } \\
\text { experiment }\end{array}$ & $\begin{array}{l}\text { Number and diam- } \\
\text { eter (in mm) of the } \\
\text { single cuttings agita- } \\
\text { tion and cleaning } \\
\text { nozzles }\end{array}$ & $\begin{array}{l}\text { Number and diameter } \\
\text { (in mm) of the single } \\
\text { backward jet nozzles }\end{array}$ \\
\hline $1: 1$ & $5 \times 7.76$ & $5 \times 7.76$ \\
$4: 5$ & $4 \times 7.76$ & $5 \times 7.76$ \\
\hline
\end{tabular}

that the ultimate pressure difference testing in this experiment may not reveal the ultimate depressurization capacity of the depressure-dominated JMB.

The depressurization capacity under real bottom hole condition of the depressure-dominated JMB with $M=1: 1$ is numerically simulated in the early section. In order to numerically analyze the pressure under the real bottom hole condition, fluid particles along the direction indicated as the red arrow that is vertically from the inlet of cuttings-suction channel to the bottom hole are selected for analyzing (Fig. 20). The vertical distance from the inlet of cuttings-suction channel to the bottom hole is $72 \mathrm{~mm}$. When $M=1: 1$, the pressure of fluid particles near the inlet of cuttings-suction channel is almost the lowest and then goes up toward the bottom hole, and accordingly the pressure difference between the annulus pressure and the bottom hole pressure ranges from 0.15 to $0.61 \mathrm{MPa}$ (Fig. 21). It is higher than the experimental results; it can conjecture that it may achieve a higher depressurization capacity in the real drilling situation with the depressure-dominated JMB. 


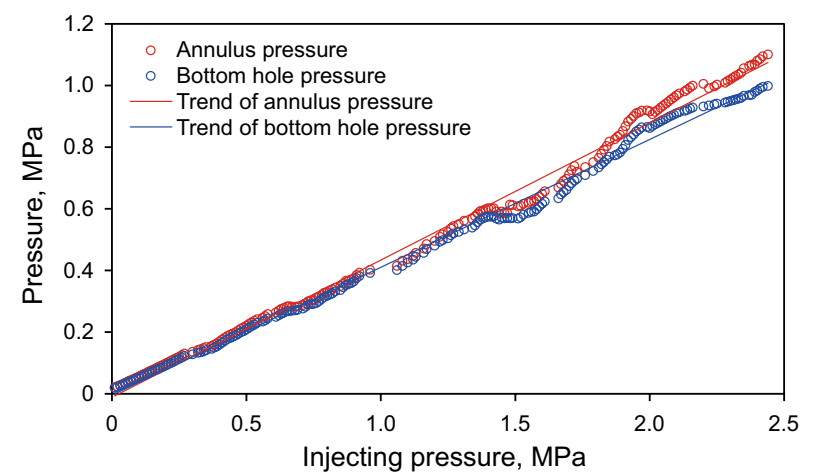

(a) Annulus pressure and bottom hole pressure

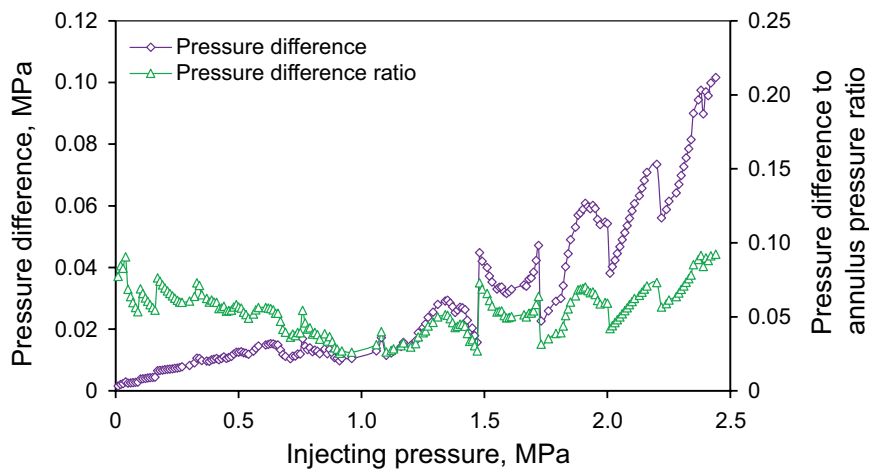

(b) Pressure difference and pressure difference ratio

Fig. 18 Pressure curves at $M=1: 1$

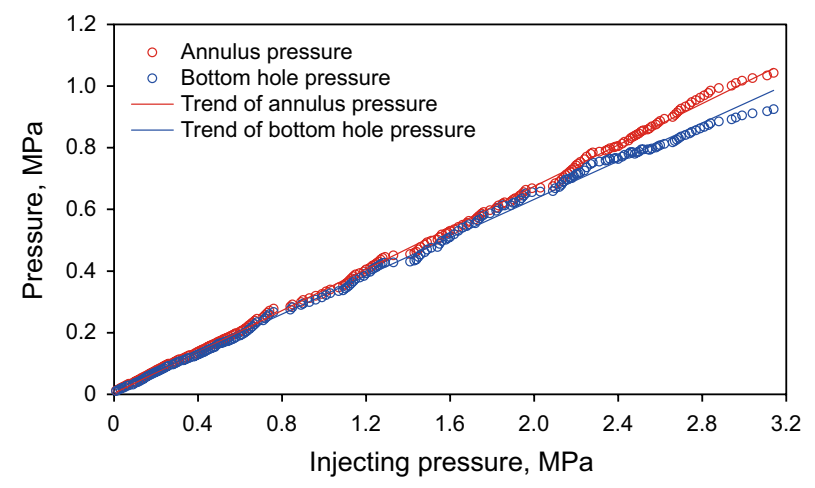

(a) Annulus pressure and bottom hole pressure

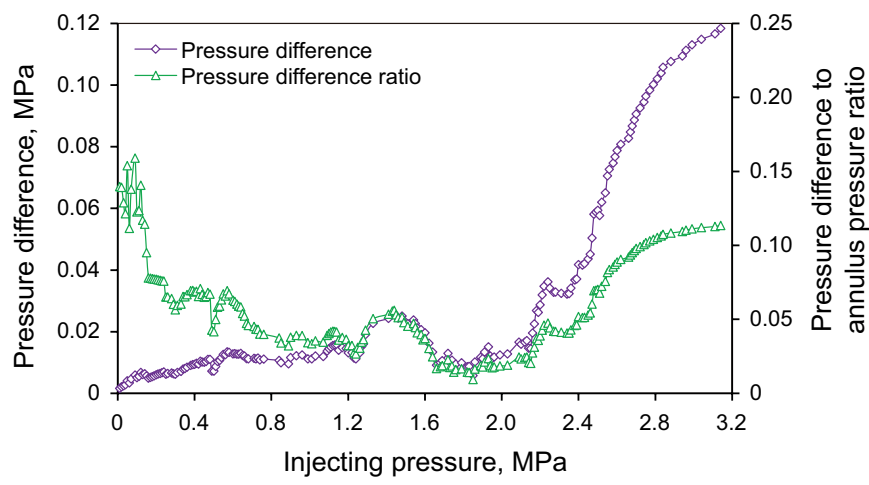

(b) Pressure difference and pressure difference ratio

Fig. 19 Pressure curves at $M=4: 5$

\section{Conclusions}

In this paper, a new type of depressure-dominated JMB is presented; meanwhile, the depressurization capacity of the depressure-dominated JMB is investigated by numerical simulations and experiments. The numerical study shows that higher fluid displacement from the backward jet nozzles than that from the cuttings agitation and cleaning nozzles helps to enhance the depressurization capacity of the depressure-dominated JMB; for both depressurization and bottom hole cleaning concern, the flow-rate ratio is suggested to be

set at approximately 1:1. Higher average jet velocity results in higher depressurization capacity of the depressure-dominated JMB. With all other parameter values being constant, lower dimensionless nozzle-to-throat-area ratio may result in higher depressurization capacity and better bottom hole cleaning of the depressure-dominated JMB, and the optimal dimensionless nozzle-to-throat-area ratio is at approximately 0.15. Experiments indicate that reducing the dimensionless flow-rate ratio may help to increase the depressurization capacity of the depressure-dominated JMB. 


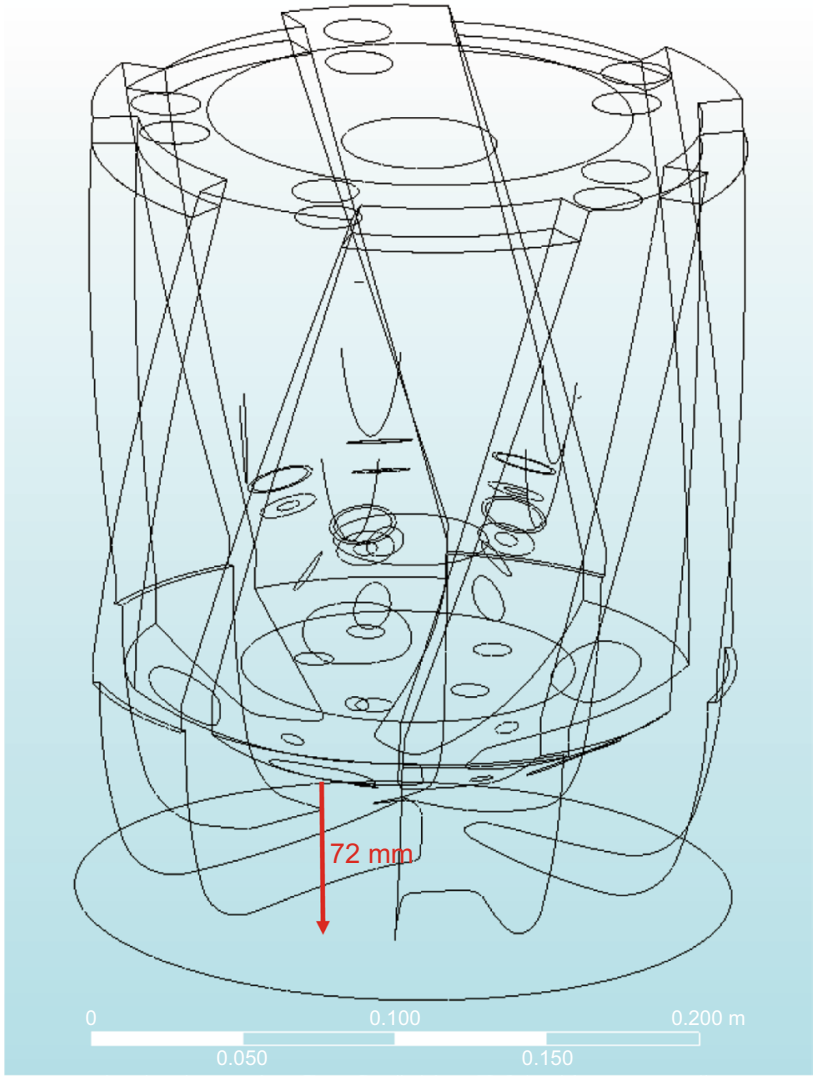

Fig. 20 Locations of fluid particles at the bottom hole along the red arrow for pressure analysis

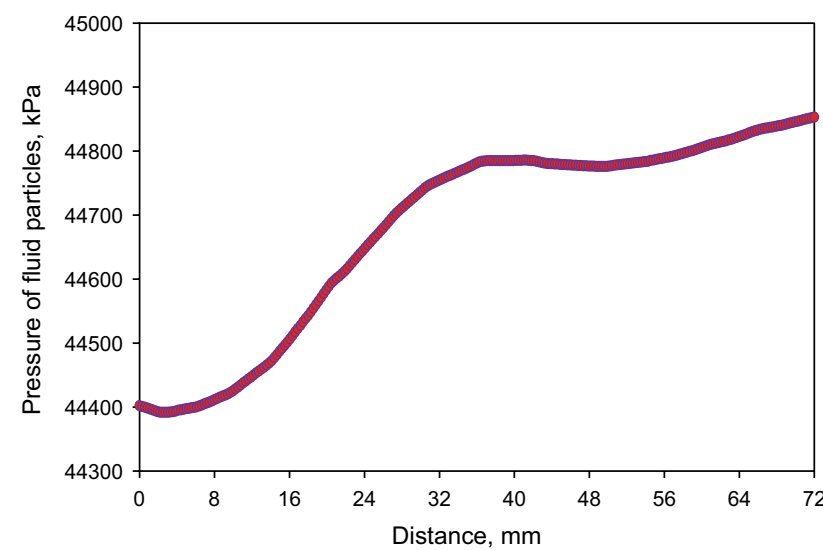

Fig. 21 Pressure of fluid particles at the bottom hole along the direction of the red arrow shown in Fig. 20

Acknowledgements This work was financially supported by the National Natural Science Foundation of China (Grant Numbers: 51804322; 51821092; 51774301; U1762214), National Key Research and Development Project (Grant Numbers: 2017ZX05009003; 2017ZX05005-005-007; 2016YFC0303303), and other projects (Grant Numbers: 2462017YJRC050, SXCU-201903, CNOOC-KJ135ZDXM37SZ05SZ).
Open Access This article is licensed under a Creative Commons Attribution 4.0 International License, which permits use, sharing, adaptation, distribution and reproduction in any medium or format, as long as you give appropriate credit to the original author(s) and the source, provide a link to the Creative Commons licence, and indicate if changes were made. The images or other third party material in this article are included in the article's Creative Commons licence, unless indicated otherwise in a credit line to the material. If material is not included in the article's Creative Commons licence and your intended use is not permitted by statutory regulation or exceeds the permitted use, you will need to obtain permission directly from the copyright holder. To view a copy of this licence, visit http://creativecommons.org/licenses/by/4.0/.

\section{References}

Ahmed RM. Mathematical modeling and experimental investigation on solids and cuttings transport. Ph.D. dissertation, Norwegian University of Science and Technology, Trondheim, Norway. 2001.

Chen X, Gao D. The maximum-allowable well depth while performing ultra-extended-reach drilling from shallow water to deepwater target. SPE J. 2018;23(01):224-36. https://doi.org/10.2118/18302 5-PA.

Chen X, Gao D, Guo B, et al. A new method for determining the minimum gas injection rate required for hole cleaning in horizontal gas drilling. J Nat Gas Sci Eng. 2014;21:1084-90. https://doi. org/10.1016/j.jngse.2014.11.009.

Chen X, Gao D, Guo B. A method for optimizing jet-mill-bit hydraulics in horizontal drilling. SPE J. 2016a;21(02):416-22. https://doi. org/10.2118/178436-PA.

Chen X, Gao D, Guo B. Optimal design of jet mill bit for jet comminuting cuttings in horizontal gas drilling hard formations. J Nat Gas Sci Eng. 2016b;28:587-93. https://doi.org/10.1016/j.jngse .2015.12.033.

Chen X, Gao D, Guo B, Feng Y. Real-time optimization of drilling parameters based on mechanical specific energy for rotating drilling with positive displacement motor in the hard formation. J Nat Gas Sci Eng. 2016c;35:686-94. https://doi.org/10.1016/j.jngse .2016.09.019.

Cao T, Yu K, Chen X, et al. Numerical and experimental investigation on the feasibility of horizontal drilling with a new type of jet mill bit. ASME J Energy Resour Technol. 2019;141(9):093101. https ://doi.org/10.1115/1.4043246.

Duan M, Miska SZ, Yu M, et al. Transport of small cuttings in extended-reach drilling. SPE Drill Compl. 2008;23(3):258-65. https://doi.org/10.2118/104192-MS.

Epelle EI, Gerogiorgis DI. CFD modelling and simulation of drill cuttings transport efficiency in annular bends: effect of particle sphericity. J Pet Sci Eng. 2018;170:992-1004. https://doi. org/10.1016/j.petrol.2018.06.041.

Fisher ES. Milling of active pharmaceutical ingredients. In: Swarbrick J, editor. Encyclopedia of pharmaceutical technology. 3rd ed. New York: Informa Healthcare; 2006. p. 2339-51.

Ford JT, Peden JM, Oyeneyin MB, et al. Experimental investigation of drilled cuttings transport in inclined boreholes. In: SPE annual technical conference and exhibition, New Orleans, 23-26 September 1990. https://doi.org/10.2118/20421-MS.

Gao D, Tan C, Tang H. Limit analysis of extended reach drilling in south China sea. Pet Sci. 2009;6(2):166-71. https://doi. org/10.1007/s12182-009-0026-8.

Hakim H, Katende A, Sagala F, et al. Performance of polyethylene and polypropylene beads towards drill cuttings transportation in horizontal wellbore. J Pet Sci Eng. 2018;165:962-9. https:// doi.org/10.1016/j.petrol.2018.01.075. 
Heshamudin NS, Katende A, Rashid HA, et al. Experimental investigation of the effect of drill pipe rotation on improving hole cleaning using water-based mud enriched with polypropylene beads in vertical and horizontal wellbores. J Pet Sci Eng. 2019;179:1173-85. https://doi.org/10.1016/j.petro 1.2019.04.086.

Hooper DW Annulus bypass peripheral nozzle jet pump pressure differential drilling tool and method for well drilling. U.S. Patent No. 4630691. 23 Dec 1986.

Hosie D, Bansal R K, Moyes P B. Apparatus and method to reduce fluid pressure in a wellbore. U.S. Patent No. 6837313. 4 Jan 2005.

Hughes WJ, Renfro JJ. Downhole drilling assembly with independent jet pump. U.S. Patent No. 6877571. 12 Apr 2005.

Kamyab M, Rasouli V. Experimental and numerical simulation of cuttings transportation in coiled tubing drilling. J Nat Gas Sci Eng. 2016;29:284-302. https://doi.org/10.1016/j.jngse.2015.11.022.

Li G, Huang Z, Tian S, et al. Research and application of water jet technology in well completion and stimulation in China. Pet Sci. 2010;7(2):239-44. https://doi.org/10.1007/s12182-010-0009-9.

Lott W G. Jet pump drilling apparatus and method. U.S. Patent No. 5,775,443. 7 Jul 1998.

Müller R H, Peters K, Becker R, et al. Nanosuspensions-a novel formulation for the iv administration of poorly soluble drugs, In: 1st World meeting APGI/APV, Budapest, 1995.

Pang B, Wang S, Lu C, et al. Investigation of cuttings transport in directional and horizontal drilling wellbores injected with pulsed drilling fluid using CFD approach. Tunn Undergr Sp Tech. 2019;90:183-93. https://doi.org/10.1016/j.tust.2019.05.001.

Shi HZ, Ji ZS, Zhao HQ, et al. Investigations into the coiled tubing partial underbalanced drilling (CT-PUBD) technique for drilling hard formations. Pet Sci. 2018;15(4):830-40. https://doi.org/10.1007/ s12182-018-0271-9.

Suryanarayana PV, Hasan ABM, Hughes WJ. Technical feasibility and applicability of a concentric jet pump in underbalanced drilling. In: SPE/IADC Underbalanced Technology Conference and Exhibition, Houston, USA, 11-12 October 2004. http://dx.doi. org/10.2118/91595-MS.

Walker S, Li J. The effect of particle size, fluid rheology, and pipe eccentricity on cuttings transport. In: SPE/ICoTA coiled tubing roundtable, Houston, 5-6 April 2000. https://doi. org/10.2118/60755-MS.

Wang FJ. Analysis of computational fluid dynamics-CFD software principle and application. Beijing: Tsinghua University Press; 2004. p. 119-24.

Yang B, Chen D, Zhang W, et al. Depressurization mechanism of the vortex methods and its current development status. Sci Technol Rev. 2012;30(23):67-73. https://doi.org/10.3981/j. issn.1000-7857.2012.23.010.

Yeu WJ, Katende A, Sagala F, et al. Improving hole cleaning using low density polyethylene beads at different mud circulation rates in different hole angles. J Nat Gas Sci Eng. 2019;61:333-43. https ://doi.org/10.1016/j.jngse.2018.11.012.

Zhang Y, Liu Y, Xu Y, et al. Drilling characteristics of combinations of different high pressure jet nozzles. J Hydro Ser B. 2011;23(3):384 90. https://doi.org/10.1016/S1001-6058(10)60127-8.

Zhu H, Deng J, He Y, et al. Reducing bottom-hole differential pressure by hydraulic jet. J China U of Pet Nat Sci. 2013;2:10. https://doi. org/10.3969/j.issn.1673-5005.2013.02.008. 